\title{
Emergência e crescimento inicial de plântulas de pimenta ornamental e celosia em substrato à base de composto de lodo de curtume
}

\author{
Germination and initial growth of ornamental Capsicum and Celosia in \\ substrate of composted tannery sludge
}

\author{
Jayara Dayany da Costa Silva ${ }^{\mathrm{I}}$ Tâmara Thays Barbosa Leal ${ }^{\mathrm{I}}$ Raul Matos Araújo ${ }^{\mathrm{I}}$ \\ Regina Lúcia Ferreira Gomes ${ }^{\mathrm{I}}$ Ademir Sérgio Ferreira de Araújo ${ }^{\mathrm{I*}}$ Wanderley José de Melo ${ }^{\mathrm{II}}$
}

\section{RESUMO}

\begin{abstract}
Há grande potencial de uso dos resíduos industriais compostados como substrato na produção de mudas de espécies ornamentais. O objetivo deste trabalho foi avaliar a emergência e o crescimento inicial de plântulas de pimenta ornamental e celosia em substratos à base de composto de lodo de curtume. $O$ experimento foi instalado em bandejas de isopor e os substratos utilizados foram: composto de lodo de curtume; composto de lodo de curtume $+10 \%$ de vermiculita; composto de lodo de curtume $+20 \%$ de vermiculita; substrato comercial à base de turfa, usado como controle. No composto de lodo de curtume, houve aumento na velocidade de emergência das plântulas apenas para pimenta ornamental. Para a fitomassa, a altura das plantas e para o comprimento das raizes, os maiores valores ocorreram nos tratamentos em que o substrato foi o composto de lodo de curtume, em relação à turfa. $O$ maior valor de fitomassa das raízes foi obtido quando o substrato foi o composto de lodo de curtume associado com $10 \%$ de vermiculita. O composto de lodo de curtume é uma alternativa potencial para uso como substrato na produção de mudas de pimenta ornamental e celosia.
\end{abstract}

Palavras-chave: resíduo industrial, compostagem, plantas ornamentais, mudas.

\section{ABSTRACT}

For composted industrial wastes have high potential to use as substrate for seedling production of ornamental species, therefore that the aim of this work was to evaluate emergency and plant growth of ornamental Capsicum and Celosia in substrate based of tannery sludge compost. The experiment was carried out in trays and substrates were: tannery sludge compost, tannery sludge compost $+10 \%$ vermiculite,

\begin{abstract}
tannery sludge compost $+20 \%$ vermiculite, commercial substrate used as control. In the tannery sludge compost there was an increase in the rate of seedling emergence only for ornamental pepper. For the plant biomass, height and root length the highest values occurred in treatments where the substrate was tannery sludge compost as compared as with commercial substrate. The higher value of root biomass was obtained when the substrate was tannery sludge composted associated with $10 \%$ vermiculite. The tannery sludge compost may be a potential alternative for use as substrate in seedling production of ornamental Capsicum and celosia.
\end{abstract}

Key words: industrial waste, composting, ornamental plant, seedling.

\section{INTRODUÇÃO}

Os curtumes produzem resíduos com elevada carga orgânica e inorgânica, os quais são conhecidos por lodo de curtume e, geralmente, são dispostos em aterros sanitários, têm manejo com custo elevado e sem garantias de segurança ao meio ambiente (ALTAFIN et al., 2004).

O processo de compostagem vem sendo proposto como uma alternativa de tratamento e reutilização de lodos para fins agrícolas (ARAÚJO et al., 2007). Durante a compostagem, os nutrientes presentes nos resíduos são convertidos, pelos microrganismos, em formas disponíveis às plantas (NDEGWA \& THOMPSON, 2001). Além disso, a

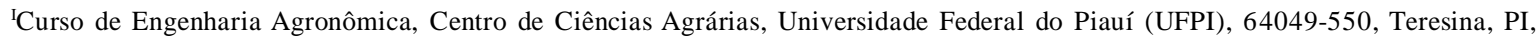
Brasil. E-mail: asfaruaj@yahoo.com.br.*Autor para correspondência.

"Departamento de Tecnologia, Faculdade de Ciências Agronômicas e Veterinárias, Universidade Estadual Paulista (UNESP), Jaboticabal, SP, Brasil. 
compostagem pode diminuir ou eliminar a toxicidade do lodo urbano e industrial (ARAÚJO \& MONTEIRO, 2005), podendo ser utilizado como substrato orgânico para produção de mudas de espécies ornamentais, por não oferecerem riscos de contaminação por elementos tóxicos à cadeia alimentar humana.

A utilização de substrato na produção de mudas tem por finalidade garantir o seu desenvolvimento adequado em curto período de tempo e com o menor custo (CUNHA et al., 2006). Na composição do substrato, a fonte orgânica é responsável pela retenção da umidade e liberação dos nutrientes que serão absorvidos pelas plantas (ANDRADE NETO et al., 1999). O substrato também tem a função de suportar o sistema radicular das mudas em crescimento (KÄMPF, 2000). Vários trabalhos relataram o uso dos lodos urbanos (SANTOS et al., 1998; TELES et al., 1999) e industriais (ALTAFIN et al., 2004) como substratos para produção de mudas.

Dentre as espécies utilizadas na floricultura, a pimenta ornamental (Capsicum sp L.) e a celosia (Celosia cristata L.) são comercializadas como plantas anuais envasadas, sendo apreciadas principalmente por causa do colorido das suas flores e frutos e, não obstante, há poucos estudos relacionados à utilização de substratos diferentes e seus efeitos na produção de mudas dessas espécies.

Dessa forma, objetivo deste trabalho foi avaliar a emergência e o crescimento inicial de plântulas de pimenta ornamental e celosia em substratos produzidos a partir da compostagem do lodo de curtume.

\section{MATERIAL E MÉTODOS}

O experimento foi conduzido em casa de vegetação no Departamento de Fitotecnia da Universidade Federal do Piauí. O lodo de curtume foi obtido no Curtume Europa, Teresina, PI. A pilha de compostagem foi constituída de lodo de curtume misturado com bagaço de cana e esterco bovino na proporção de 1:1:3 (v:v:v). O bagaço de cana (relação C/N 154) e o esterco bovino (relação $\mathrm{C} / \mathrm{N}$ 9) foram obtidos na Usina Comvap, no município de União (PI) e no Departamento de Zootecnia da UFPI, respectivamente. $\mathrm{O}$ processo de compostagem foi conduzido durante 90 dias, utilizando-se o método de pilhas revolvidas (USDA, 1980). Ao final da compostagem, foram retiradas amostras em três pontos da pilha para avaliação da umidade, matéria orgânica e conteúdo em nutrientes, realizadas no Departamento de Tecnologia da Faculdade de Ciências Agrárias e Veterinárias da Universidade Estadual Paulista, em Jaboticabal, SP (Tabela 1).
Tabela 1 - Características químicas do composto de lodo de curtume e da turfa, utilizados como substrato para pimenta ornamental e celosia.

\begin{tabular}{lcl}
\hline Atributos & $\begin{array}{c}\text { Composto de } \\
\text { lodo de curtume }\end{array}$ & Turfa \\
\hline Umidade a $65^{\circ} \mathrm{C}(\%)$ & 42,70 & 45,6 \\
$\mathrm{C}_{\text {org }}\left(\mathrm{g} \mathrm{kg}^{-1}\right)$ & 187,50 & 298,2 \\
Substâncias húmicas $\left(\mathrm{g} \mathrm{C}_{\text {org kg }}{ }^{-1}\right)$ & 9,72 & 5,5 \\
Ácidos húmicos $\left(\mathrm{g} \mathrm{C}_{\text {org kg }} \mathrm{kg}^{-1}\right)$ & 5,45 & 3,1 \\
Ácidos fúlvicos $\left(\mathrm{g} \mathrm{C}_{\text {org kg }}\right)$ & 4,22 & 2,6 \\
$\mathrm{Humina}\left(\mathrm{g} \mathrm{C}_{\mathrm{org}} \mathrm{kg}^{-1}\right)$ & 177,89 & 102,7 \\
$\mathrm{~N}\left(\mathrm{~g} \mathrm{~kg}^{-1}\right)$ & 1,28 & 0,9 \\
$\mathrm{P}\left(\mathrm{g} \mathrm{kg}^{-1}\right)$ & 4,02 & 3,6 \\
$\mathrm{~K}\left(\mathrm{~g} \mathrm{~kg}^{-1}\right)$ & 3,25 & 3,2 \\
$\mathrm{Ca}\left(\mathrm{g} \mathrm{kg}^{-1}\right)$ & 95,33 & 4,9 \\
$\mathrm{Mg}\left(\mathrm{g} \mathrm{kg}^{-1}\right)$ & 6,80 & 2,2 \\
$\mathrm{~S}\left(\mathrm{~g} \mathrm{~kg}^{-1}\right)$ & 9,39 & 0,8 \\
$\mathrm{Cu}\left(\mathrm{mg} \mathrm{kg}^{-1}\right)$ & 17,8 & 27,9 \\
$\mathrm{Fe}\left(\mathrm{mg} \mathrm{kg}^{-1}\right)$ & 5171,6 & 58,0 \\
$\mathrm{Mn}\left(\mathrm{mg} \mathrm{kg}^{-1}\right)$ & 1848,7 & 83,7 \\
$\mathrm{Zn}\left(\mathrm{mg} \mathrm{kg}^{-1}\right)$ & 141,67 & 34,7 \\
$\mathrm{Mo}\left(\mathrm{mg} \mathrm{kg}^{-1}\right)$ & 9,28 & 3,1 \\
\hline
\end{tabular}

Os substratos testados foram: composto de lodo de curtume; composto de lodo de curtume $+10 \%$ de vermiculita; composto de lodo de curtume $+20 \%$ de vermiculita; substrato comercial á base de turfa (Germina $\left.{ }^{\circledR}\right)$, utilizado como controle, distribuídos em bandejas de isopor com 128 células. A composição química do composto de lodo de curtume e da turfa encontra-se na tabela 1. Cada célula foi preenchida com o devido substrato e nela foram colocadas duas sementes das espécies das plantas em estudo, a $1 \mathrm{~cm}$ de profundidade, totalizando 16 células por tratamento para cada espécie. As bandejas foram colocadas em casa de vegetação com sombrite $(75 \%)$ e irrigadas diariamente com auxílio de regador.

As avaliações da emergência das plântulas (número de plântulas emergidas sobre o substrato após a semeadura) foram realizadas aos 10, 20 e 30 dias para a pimenta ornamental e aos 5, 7 e 10 dias para a celosia. Ao final do período de emergência das plântulas de pimenta ornamental e celósia (aos 30 e 10 dias, respectivamente), foram efetuados desbastes, deixando-se uma plântula por célula. Aos 60 e 90 dias após a emergência, respectivamente, para a celosia e a pimenta ornamental, foram avaliadas a massa fresca e seca da parte aérea e raiz, o comprimento da parte aérea e do sistema radicular, o número de folhas e a forma do tubete (conformação e aspecto do sistema radicular medido por escala de notas). As notas utilizadas variaram de 0 (tubete mal formado) a 5 (tubete bem 
formado). As plantas foram removidas da bandeja com os substratos, procedendo-se, em seguida, à remoção desses substratos e a lavagem cuidadosa do sistema radicular com água corrente. O comprimento da parte aérea e do sistema radicular foi avaliado com auxílio de régua milimetrada. As plantas foram então cortadas na altura do colo para separar parte aérea e raiz, cuja massa verde foi devidamente avaliada. Em seguida, a parte aérea e as raízes foram colocadas para secar em estufa com circulação forçada de ar e mantida a $65^{\circ} \mathrm{C}$ até obtenção de peso constante.

Odelineamento experimental foi inteiramente casualizado com seis repetições. Os resultados obtidos foram submetidos à análise da variância e, quando o teste $\mathrm{F}$ foi significativo, procedeu-se à comparação de médias pelo teste de Tukey $(\mathrm{P}<0,05)$. Na comparação das notas atribuídas para os tubetes, foi utilizado o teste não paramétrico de Kruskal-Wallis.

\section{RESULTADOS E DISCUSSÃO}

Não houve diferenças entre os substratos utilizados com relação à emergência de plântulas de celosia aos 5, 7 e 10 dias após o plantio (Tabela 2). No caso da pimenta ornamental, aos dez dias houve emergência de plântulas apenas nos substratos aos quais foi adicionado composto de lodo de curtume. Aos vinte dias, observou-se emergência de plântulas em todos os substratos testados, entretanto o melhor resultado foi observado quando se utilizou o substrato à base de composto de lodo de curtume puro, com maior número de plântulas emergidas. Aos trinta dias, não foram observadas diferenças entre os substratos com relação ao número de plântulas emergidas.
Pelos resultados, observa-se que não houve toxicidade do lodo de curtume compostado sobre a emergência das plântulas de pimenta ornamental e celosia, sugerindo que o processo de compostagem pode reduzir a toxicidade do resíduo industrial, conforme reportado por ARAÚJO \& MONTEIRO (2005). Esses autores avaliaram a emergência de plântulas de soja na presença de lodo têxtil puro e compostado e observaram maior velocidade de emergência de plântulas na presença de lodo têxtil compostado, quando comparado ao resíduo puro. Os substratos à base de composto de lodo de curtume proporcionaram rápida emergência das plântulas de pimenta ornamental, o que pode ter ocorrido devido às propriedades físicas e químicas desses substratos. A velocidade de emergência é importante na obtenção de um bom estabelecimento das plântulas, condição necessária para tolerância a estresses ambientais (CARVALHO \& NAKAGAWA, 2000).

Os valores de massa fresca e seca da parte aérea das plântulas de pimenta ornamental e celosia foram superiores quando se utilizou os substratos com composto de lodo de curtume, comparado com o substrato à base de turfa (Tabela 3). Isso indica que o composto de lodo de curtume proporcionou o desenvolvimento das plântulas dessas espécies, provavelmente em função do seu conteúdo de nutrientes. Esses resultados corroboram outros estudos que apontaram efeitos positivos do uso de resíduos urbanos e industriais no aumento da fitomassa de plantas (SANTOS et al., 1998; ARAÚJO et al., 2005; ARAÚJO et al., 2007). Os maiores valores de fitomassa foram encontrados nas plântulas que cresceram no substrato constituído pela mistura de composto de lodo

Tabela 2 - Emergência de plântulas de pimenta ornamental e celosia em bandejas de isopor, em função de diferentes substratos.

\begin{tabular}{|c|c|c|c|c|c|c|}
\hline \multirow[t]{2}{*}{ Tratamentos } & \multicolumn{2}{|c|}{ 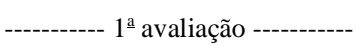 } & \multicolumn{2}{|c|}{----------- 2ª avaliação------------ } & \multicolumn{2}{|c|}{------- 3ª avaliação ------- } \\
\hline & Pimenta* & Celosia** & Pimenta & Celosia & Pimenta & Celosia \\
\hline Composto & $4 \mathrm{~b}$ & $26 \mathrm{a}$ & $26 \mathrm{a}$ & $26 \mathrm{a}$ & $31 \mathrm{a}$ & $30 \mathrm{a}$ \\
\hline CV10 & $4 \mathrm{~b}$ & $32 \mathrm{a}$ & $16 \mathrm{~b}$ & $32 \mathrm{a}$ & $32 \mathrm{a}$ & $32 \mathrm{a}$ \\
\hline CV20 & 9 a & $30 \mathrm{a}$ & $18 \mathrm{~b}$ & $32 \mathrm{a}$ & $32 \mathrm{a}$ & $32 \mathrm{a}$ \\
\hline Turfa & $0 \mathrm{c}$ & $32 \mathrm{a}$ & $12 \mathrm{~b}$ & $32 \mathrm{a}$ & $31 \mathrm{a}$ & $32 \mathrm{a}$ \\
\hline
\end{tabular}

Médias seguidas da mesma letra não diferem entre si pelo teste de Tukey a $5 \%$ de probabilidade.

$\mathrm{CV} 10=$ composto de lodo de curtume $+10 \%$ de vermiculita. CV20 $=$ composto de lodo de curtume $+20 \%$ de vermiculita.

*Pimenta ornamental: $1^{\underline{a}}$ avaliação aos 10 dias; $2^{\underline{a}}$ avaliação aos 20 dias; e $3^{\underline{a}}$ avaliação aos 30 dias.

**Celosia: $1^{\underline{a}}$ avaliação aos 5 dias; $2^{\underline{a}}$ avaliação aos 7 dias; e $3^{\underline{a}}$ avaliação aos 10 dias. 
Tabela 3 - Massa da parte aérea e de raízes de plântulas de pimenta ornamental e celosia em bandejas de isopor, tendo como substrato turfa e composto de lodo de curtume, associado ou não com vermiculita.

\begin{tabular}{|c|c|c|c|c|c|c|c|c|}
\hline \multirow{3}{*}{ Tratamentos } & \multicolumn{4}{|c|}{----------Massa Fresca (mg plântula ${ }^{-1}$ )------------ } & \multicolumn{4}{|c|}{ 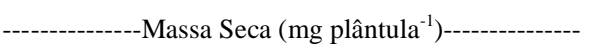 } \\
\hline & \multicolumn{2}{|c|}{------- Parte Aérea ------- } & \multicolumn{2}{|c|}{-------- Raiz ------- } & \multicolumn{2}{|c|}{------- Parte Aérea ------- } & \multicolumn{2}{|c|}{------- Raiz ------- } \\
\hline & Pimenta & Celosia & Pimenta & Celosia & Pimenta & Celosia & Pimenta & Celosia \\
\hline Composto & $773,3 \mathrm{a}$ & $432,0 \mathrm{~b}$ & $493,3 b$ & $293,4 b$ & $90,3 \mathrm{a}$ & $51,7 \mathrm{~b}$ & $42,5 b$ & $30,2 b$ \\
\hline CV10 & $760,0 \mathrm{a}$ & $557,1 \mathrm{a}$ & $593,3 \mathrm{a}$ & $401,2 \mathrm{a}$ & $92,4 a$ & $72,9^{a}$ & $57,1^{\mathrm{a}}$ & $43,6 a$ \\
\hline CV20 & $546,6 b$ & $425,6 b$ & $560,0 \mathrm{a}$ & $317,0 \mathrm{~b}$ & $91,9 \mathrm{a}$ & $49,2 b$ & $56,5^{\mathrm{a}}$ & $35,9 b$ \\
\hline Turfa & $318,3 c$ & $212,9 \mathrm{c}$ & $103,3 \mathrm{c}$ & $139,3 \mathrm{c}$ & $50,3 b$ & $35,0 \mathrm{c}$ & $35,2 \mathrm{c}$ & $17,4 \mathrm{c}$ \\
\hline $\mathrm{CV}(\%)$ & 15,5 & 11,4 & 19,7 & 17,4 & 11,5 & 12,6 & 11,2 & 9,3 \\
\hline
\end{tabular}

Médias seguidas da mesma letra não diferem entre si pelo teste de Tukey a $5 \%$ de probabilidade.

CV10 $=$ composto de lodo de curtume $+10 \%$ de vermiculita. CV20 $=$ composto de lodo de curtume $+20 \%$ de vermiculita

de curtume e $10 \%$ de vermiculita, pois esta contribui para condicionar o substrato, melhorando as propriedades físico-hídricas (MELO et al., 2003), estruturação e a capacidade de retenção de água (MINAMI, 1984), proporcionando uma excelente relação água/ar, favorecendo o desenvolvimento das plântulas.

Para a altura das plântulas, os maiores valores foram obtidos quando o substrato foi à base de composto de lodo de curtume e $10 \%$ de vermiculita (Tabela 4). A altura da planta é considerada um dos atributos mais importantes para estimar o padrão de qualidade de mudas (CUNHA et al., 2006). Nesse sentido, os resultados confirmam o efeito positivo do composto de lodo de curtume como substrato para produção de mudas de pimenta ornamental e celosia, proporcionando mudas vigorosas e adequadas ao transplantio. Para o comprimento das raízes de pimenta, os maiores valores foram encontrados quando os substratos foram à base de composto de lodo de curtume, em comparação ao substrato de turfa. No caso da celosia, o maior valor foi observado quando se utilizou o substrato à base de composto de lodo de curtume e $10 \%$ de vermiculita.

O número de folhas da pimenta ornamental e da celosia foram maiores nos tratamentos em que o substrato continha composto de lodo de curtume (Tabela 4), produzindo mudas com maior área foliar. A área foliar pode ser considerada como um índice de qualidade das mudas, dada a importância dos órgãos fotossintetizantes na produção biológica da planta (SCALON et al., 2003).

Os substratos à base de composto de lodo de curtume proporcionaram melhor conformação dos

Tabela 4 - Comprimento da parte aérea e raiz, número de folhas de pimenta ornamental e celosia e a forma do tubete aos 90 e 60 dias após a semeadura, respectivamente, em bandejas de isopor, tendo como substrato turfa e composto de lodo de curtume, associado ou não com vermiculita.

\begin{tabular}{|c|c|c|c|c|c|c|c|c|}
\hline \multirow{3}{*}{ Tratamentos } & \multicolumn{4}{|c|}{ 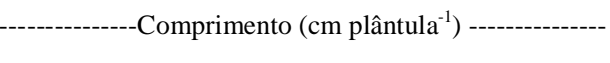 } & \multirow{2}{*}{\multicolumn{2}{|c|}{$\begin{array}{l}\text { Número de folhas } \\
\left(\mathrm{n}^{\underline{0}} \text { plântula }\right.\end{array}$}} & \multirow{2}{*}{\multicolumn{2}{|c|}{ Forma do tubete (Nota) }} \\
\hline & \multicolumn{2}{|c|}{--- Parte aérea --- } & \multicolumn{2}{|c|}{---- Raiz ---- } & & & & \\
\hline & Pimenta & Celosia & Pimenta & Celosia & Pimenta & Celosia & Pimenta & Celosia \\
\hline Composto & $88,8 \mathrm{a}$ & $30,4 \mathrm{~b}$ & $85,9 \mathrm{a}$ & $27,2 \mathrm{~b}$ & $24 \mathrm{a}$ & $10 \mathrm{~b}$ & $5,0 \mathrm{a}$ & $2,4 \mathrm{~b}$ \\
\hline CV10 & $90,1 \mathrm{a}$ & $45,8 \mathrm{a}$ & $83,0 \mathrm{a}$ & $38,6 \mathrm{a}$ & $22 \mathrm{a}$ & $15 \mathrm{a}$ & $5,0 \mathrm{a}$ & $4,0 \mathrm{a}$ \\
\hline CV20 & 86,8 a & $36,9 \mathrm{~b}$ & $88,5 \mathrm{a}$ & $30,3 \mathrm{~b}$ & $19 \mathrm{ab}$ & $9 \mathrm{~b}$ & $4,8 \mathrm{a}$ & $3,0 \mathrm{ab}$ \\
\hline Turfa & $62,1 \mathrm{~b}$ & $31,4 \mathrm{~b}$ & $66,5 \mathrm{~b}$ & $25,0 \mathrm{~b}$ & $15 \mathrm{~b}$ & $8 \mathrm{~b}$ & $3,8 \mathrm{~b}$ & $2,0 \mathrm{~b}$ \\
\hline CV (\%) & 7,1 & 9,1 & 8,6 & 10,4 & 13,2 & 11,5 & - & - \\
\hline
\end{tabular}

Médias seguidas da mesma letra não diferem entre si pelo teste de Tukey a 5\% de probabilidade.

$\mathrm{CV} 10=$ composto de lodo de curtume $+10 \%$ de vermiculita. CV20 $=$ composto de lodo de curtume $+20 \%$ de vermiculita.

* Escala de notas: 0 (tubete mal formado) a 5 (tubete bem formado). Médias seguidas da mesma letra não diferem entre si pelo teste não paramétrico de Kruskal-Wallis. 


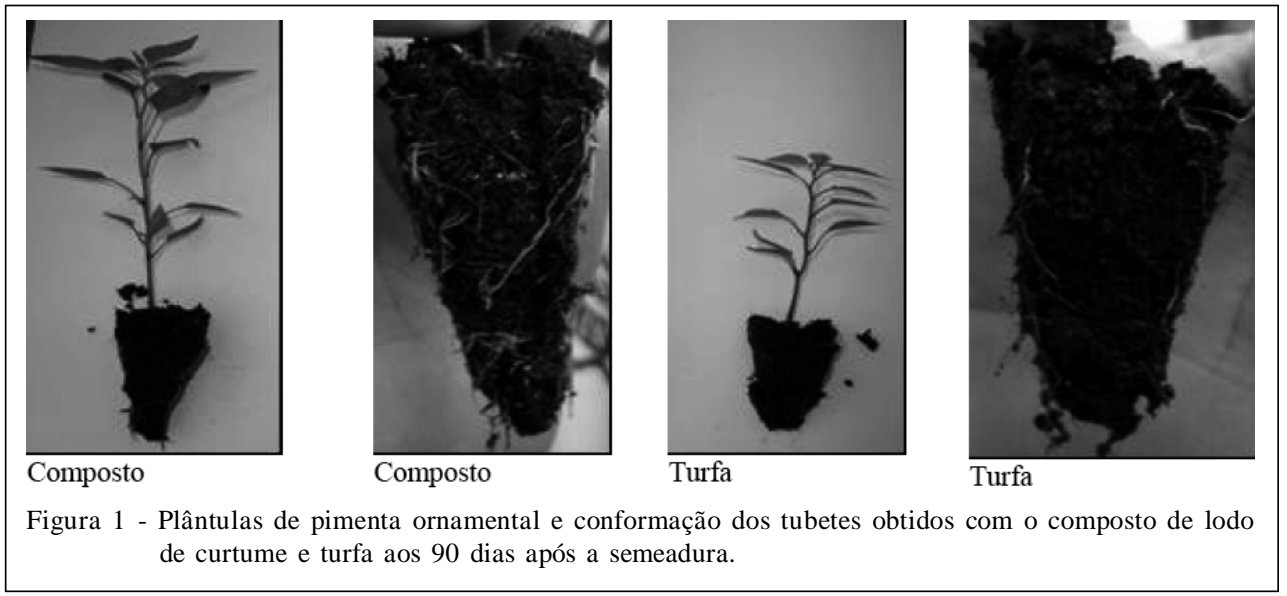

tubetes em relação á turfa (Tabela 4), de modo que as maiores notas, que variaram de 2,0 a 5,0, foram conferidas para os tratamentos em que o composto estava presente. Pelos dados da figura 1, observa-se enraizamento mais homogêneo das plântulas de pimenta ornamental no tubete formado com o substrato à base de composto de lodo de curtume, indicando boas condições ao crescimento radicular. $\mathrm{O}$ enraizamento mais homogêneo é de grande importância, conforme mencionado por MINAMI (1995), o qual relatou que quanto maior a homogeneidade e volume de raízes, maior será a quantidade de nutrientes disponíveis no intervalo entre o transplantio e a formação de novas raízes. Além disso, FILGUEIRA (2003) afirmou que um bom enraizamento favorece o reinício do desenvolvimento da planta, após o choque do processo de transplantio. Dessa forma, com o uso do substrato à base de composto de lodo de curtume, há possibilidade de se produzir mudas mais adequadas para o transplantio, proporcionando maior capacidade de pegamento em condições de vaso ou de campo.

\section{CONCLUSÃO}

Os substratos à base de composto de lodo de curtume proporcionam rápida emergência de plântulas de pimenta ornamental. O composto de lodo de curtume associado com $10 \%$ de vermiculita produz melhor enraizamento e conformação de tubete, além de favorecer o desenvolvimento das mudas de pimenta ornamental e celosia.

\section{AGRADECIMENTOS}

Ao Conselho Nacional de Desenvolvimento Científico e Tecnológico $(\mathrm{CNPq})$, pelo auxílio financeiro no desenvolvimento do projeto de pesquisa e pela bolsa de produtividade em pesquisa.

\section{REFERÊNCIAS}

ALTAFIN, V.L. et al. Utilização de lodo de fosfatização na produção de mudas de espécies nativas. Engenharia Ambiental, v.1, n.1, p.45-50, 2004.

ANDRADE NETO, A. et al. Avaliação de substratos alternativos e tipo de adubação para a produção de mudas de cafeeiro em tubetes. Ciência e Agrotecnologia, v.23, n.2, p.270-280, 1999.

ARAÚJO, A.S.F.; MONTEIRO, R.T.R. Plant bioassays to assess toxicity of textile sludge compost. Scientia Agricola, v.62, n.3, p.286-290, 2005. Disponível em: <http://www.scielo.br/ s cie lo.php? s c ript $=$ sci_art text \& pi d = S 0103 $90162005000300013 \& \operatorname{lng}=$ pt\&nrm=iso\&tlng=en>. Acesso em: 25 maio, 2010. doi: 10.1590/S0103-90162005000300013.

ARAÚJO, A.S.F. et al. Composto de lodo têxtil em plântulas de soja e trigo. Pesquisa Agropecuária Brasileira, v.40, n.6, p.549-554, 2005. Disponível em: <http:// www.scielo.br/ s c i e lo.ph p s c ri pt $=$ s c i_art text \& pi d = S $0100-$ $204 X 2005000600004 \& \operatorname{lng}=e n \& n r m=i s o \& t \operatorname{lng}=p t>$. Acesso em: 25 maio, 2010. doi: 10.1590/S0100-204X2005000600004.

ARAÚJO, A.S.F. et al. Effect of composted textile sludge on growth, nodulation and nitrogen fixation of soybean and cowpea. Bioresource Technology, v.98, p.1028-1032, 2007. Disponível em: 〈http//:dx.doi.org/10.1016/j.biortech.2006.04.028>. Acesso em: 24 abr. 2010. doi: 10.1016/j.biortech.2006.04.028.

CARVAlho, N.M.; NAKAGAWA, J. Sementes: ciência, tecnologia e produção. 4.ed. Jaboticabal: FUNEP, 2000. 588p.

CUNHA, A.M. et al. Efeito de diferentes substratos sobre o desenvolvimento de mudas de Acacia sp. Revista Árvore, v.30, n.2, p.207-214, 2006.

FILGUEIRA, F.A.R. Novo manual de olericultura: agrotecnologia moderna na produção e comercialização de hortaliças. 2.ed. Viçosa: UFV, 2003. 421p.

KÄMPF, A.N. Seleção de materiais para uso como substrato. In: KAMPF, A.N. (Ed.) Substrato para plantas: a base da produção vegetal em recipientes. Porto Alegre: Gêneses, 2000. p.139-145. 
MELO, B. et al. Tipos de fertilizações e diferentes substratos na produção de mudas de cafeeiro (Coffea arabica $\mathrm{L}$.) em tubetes. Bioscience Journal, v.19, n.1, p.33-42, 2003.

MINAMI, K. Vermiculita na horticultura. Piracicaba:Esalq, 1984. 20p.

MINAMI, K. Produção de mudas de alta qualidade em horticultura. São Paulo: T.A. Queiroz, 1995. $85 \mathrm{p}$

NDEGWA, P.M.; THOMPSON, S.A. Integrating composting and vermicomposting in treatment and bioconversion of biosolids. Bioresource Technology, v.76, p.107-112, 2001. Disponível em: <http//: http://dx.doi.org/10.1016/S09608524(00)00104-8>. Acesso em: 24 abr. 2010. doi: 10.1016/ S0960-8524(00)00104-8.
SANTOS, I.C. et al. Efeitos do composto orgânico de lixo urbano na produção de alface. Acta Scientiarum, v.20, n.3, p.275-280, 1998.

SCALON, S.P.Q. et al. Crescimento inicial de mudas de Bombacopsis glabra (Pasq.) A. Robyns sob condição de sombreamento. Revista Árvore, v. 27, p.753-758, 2003.

TELES, C.R. et al. Produção de lodo de esgoto em lagoas de estabilização e o seu uso no cultivo de espécies florestais na região sudoeste do Brasil. Sanare, v.12, n.1, p.53-60, 1999.

UNITED STATES DEPARTMENT OF AGRICULTURE. Manual for composting of sewage sludge by the Beltsville aerated-pile method. Washington:USDA-EPA, 1980. 65p. 